\title{
Multiple Vascular Anomalies in the Abdomen - A Gross Anatomical Study
}

\author{
Múltiples Anomalías Vasculares en el Abdomen - Un Estudio Anatómico Macroscópico \\ "Tony Jacob; "Vishal Modgil; "Kum Kum Rana \& *"Srijit Das
}

JACOB, T.; MODGIL, V.; RANA, K. K. \& DAS, S. Multiple vascular anomalies in the abdomen - A gross anatomical study. Int. J. Morphol., 26(3):563-566, 2008.

SUMMARY: Knowledge of the branching pattern of the abdominal aorta is clinically important for any abdominal surgeon operating on parts of the gut or neighboring structures like the suprarenals, spleen, pancreas, liver, kidneys and ureter. The presence of abnormal inferior phrenic artery associated with aberrant branch from the celiac trunk supplying the pancreas and duodenum is a rare anomaly. In the present case, we observed four branches of the celiac artery i.e. (a) left gastric artery (b) common hepatic artery (c) splenic artery and (d) an aberrant branch, which took a course inferiorly towards the pancreas. The aberrant artery supplied the body of the pancreas and gave a branch which supplied the horizontal part of the duodenum and then entered the transverse mesocolon to supply the hepatic flexure and some portions of the ascending and the transverse colon. The inferior phrenic artery was absent on the left side. Concomitant anomalies of such type are to be kept in mind by the surgeon, while operating cases of carcinoma head of pancreas and performing kidney transplantations.

KEY WORDS: Anomaly; Celiac trunk; Branch; Inferior phrenic; Artery; Pancreas; Duodenum.

\section{INTRODUCTION}

The celiac axis is a wide ventral branch measuring $1.25 \mathrm{~cm}$ in length below the aortic hiatus, dividing into left gastric, common hepatic and splenic arteries. Occasionally, the celiac axis may also give rise to the inferior phrenic artery (Standring, 2005).

Most of the terminal branches of the abdominal aorta are end arteries, but they have extensive anastomosis before forming the vasa recta. Knowledge of the anastomotic and branching patterns are a pre-requisite for a safe and successful surgery that is likely to involve vascular trees.

The foregut, midgut and the hindgut are supplied by the celiac trunk, superior mesenteric and the inferior mesenteric arteries, respectively. The lateral branches of the aorta, supply the derivatives of the intermediate mesoderm that gives rise to the urogenital ridge, i.e. renal arteries and gonadal vessels. The posterolateral branches supply the body wall, which includes the inferior aspect of the diaphragm, posterior abdominal wall and the related structures and fascia and these include the inferior phrenic arteries and the lumbar arteries.
Anomalies pertaining to the celiac trunk and its branches have been reported in past research studies. There are reports of celiac trunk dividing into four branches, with an extra branch named as 'dorsal pancreatic artery' in addition to the usual three branches namely left gastric, hepatic and the splenic arteries (Karakose et al., 2006). A past report had also defined the origin of the inferior phrenic from the celiac trunk (Cavdar et al., 1998). There are reports of an aberrant hepatic artery arising from the celiac trunk (Yamaki et al., 1995). Although the anomalies pertaining to the celiac axis are not so uncommon, concomitant absence of inferior phrenic artery associated with aberrant arterial branch from the celiac axis is a rare entity.

The CT and MR based angiographic studies help the surgeon to visualize the vascular patterns before approaching an area of interest. This allows the surgeon to make an informed choice when facing an abnormal configuration of blood vessels rather than "Hamlet-ian" choice of "to be or not to be'. In the present study, we discuss the clinical implications of multiple vascular anomalies in the abdomen.

\footnotetext{
* Department of Anatomy, Maulana Azad Medical College, New Delhi-110002, India

** Department of Anatomy, Universiti Kebangsaan, 50300 Kuala Lumpur, Malaysia.
} 


\section{MATERIAL AND METHOD}

Forty-two embalmed cadavers $($ male $=40$, female $=2$ ) who died of natural causes, were taken for the study, which was conducted in the Department of Anatomy, Maulana Azad Medical College, New Delhi, India. We excluded any cadaver which showed signs of any trauma or surgical scars on the abdomen. The age of the cadaver varied from 20- 80 years.

Careful dissection of the abdomen was done and the vascular structures were displayed. We used a Olympus 500 UZ (6.0 megapixals, 10X optical zoom), for taking appropriate photographs (Fig.1).

\section{RESULTS}

The anomalous branching pattern of the celiac axis was observed in a male cadaver, aged 60 years $(2.5 \%)$. None of the other 39 cases had any anomalous branching pattern of the celiac axis $(97.5 \%)$.

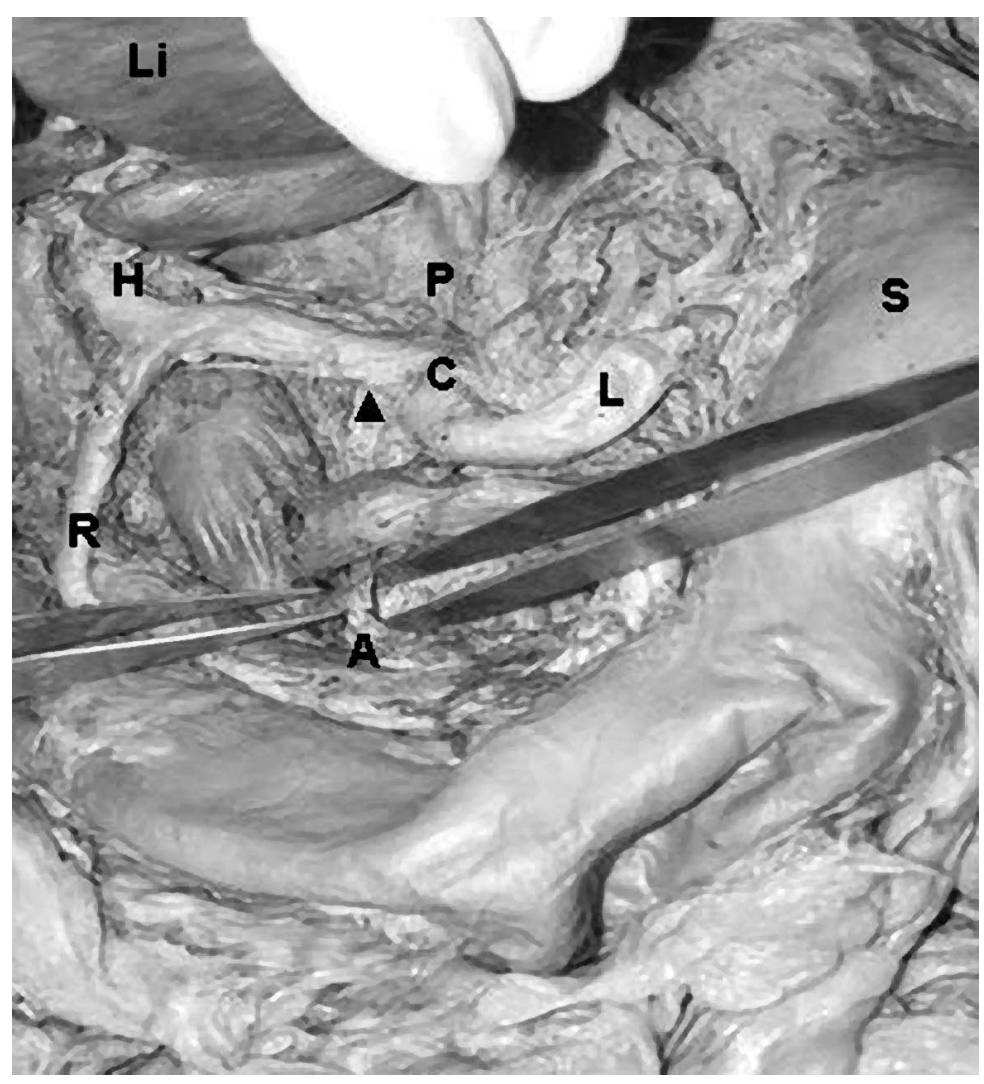

Fig. 1. Photograph of dissected region of the abdomen showing: L. Left gastric artery; H. Hepatic artery; R. Right gastric; Li. Liver; P. Peritoneum; C. Celiac trunk; A. Aberrant branch from celiac trunk; S. Stomach. The origin of the aberrant artery is marked with symbols.
On careful observation, we observed that the celiac axis had four branches: (a) left gastric artery, (b) common hepatic artery, (c) splenic artery and (d) an aberrant branch, which took a course inferiorly towards the pancreas (' $\mathrm{A}$ ' in Fig.1).

The aberrant artery traversed a course posteriorly and supplied the body of the pancreas. It also supplied a branch to the horizontal part of the duodenum, entered the transverse mesocolon and supplied the hepatic flexure and portions of the ascending and transverse colon. This artery was about 8 $\mathrm{mm}$ in diameter. It was tortuous and was about $11 \mathrm{~cm}$ long before it entered the transverse mesocolon. The part traversing the transverse mesocolon towards the hepatic flexure was $10 \mathrm{~cm}$ in length. It gave right and left branches that participated in the formation of the marginal artery. There were no separate middle colic artery arising from the superior mesenteric artery.

The superior mesenteric artery was entirely intraperitoneal. It entered the root of the mesentery $1 \mathrm{~cm}$ from its origin, $5 \mathrm{~mm}$ inferior to the origin of the celiac axis. The duodenum, pancreas and the inferior layer of the transverse mesocolon had the root of the mesentery attached to them. The root did not attach to the posterior abdominal wall. The superior mesenteric artery gave inferior pancreaticoduodenal, ileocolic, right colic and ileal and jejunal branches. The inferior mesenteric artery was normal and had left colic and sigmoid branches, which participated in the formation of the marginal artery.

The right renal artery gave rise to the middle suprarenal branches, right testicular artery and a large aberrant branch arising $3 \mathrm{~cm}$ from the hilum of the right kidney. This aberrant artery was $7 \mathrm{~mm}$ in diameter and tortuously ascended posterior to the inferior vena cava. It gave suprarenal branches and branches to the posterior abdominal wall and inferior phrenic branches to both sides of the inferior aspect of the diaphragm. It pierced the central tendon of the diaphragm lateral to the inferior vena cava and anterior to the right phrenic nerve. It also gave branches to the superior aspect of the diaphragm and the posterior mediastinum. There were no separate inferior phrenic arteries, which arose from the abdominal aorta .The inferior phrenic artery on the left side was absent. The testicular arteries and lumbar arteries were normal in origin and extent. 


\section{DISCUSSION}

In recent times, the trend in surgical branches is to move towards minimal invasive surgery for reasons of decreased morbidity and mortality, if the patient is selected carefully and investigated properly. Since, it was developed by Dubois et al. (1989), the laparoscopy-assisted surgery has become a low-invasive surgical option used primarily for cholecystectomy. In 1994, the use of laparoscopy-assisted surgery to treat gastric cancer was developed in Japan (Kitano et al., 1994). Laparoscopy-assisted distal gastrectomy is less invasive than open surgery. However, one disadvantage of laparoscopy-assisted distal gastrectomy is that it is difficult to obtain an image of the entire lesion. In addition, using this approach, we cannot manipulate lesions directly. For these reasons, a relatively long intra-operative time is required to deal with the origins of arteries and veins, of which the particular anatomy can vary greatly from case to case (Azagra et al.,1999).

Anatomical variations of the celiac trunk and superior mesenteric artery are not infrequent. Knowledge of the existing aberrations is important in planning and conducting surgical or radiological procedures (Oran et al., 2001). A description of anomalies in the first two unpaired midline branches of the abdominal aorta. The celiac trunk was unusually long. It gave a small branch which passed to the left crus of the diaphragm. This branch also gave the left superior suprarenal artery. The main trunk of the celiac trunk ended in a T-shaped bifurcation. One limb of the $\mathrm{T}$ was the right gastric artery and the other gave off the hepatic artery proper and continued as the gastroduodenal and pancreatico-duodenal system, as usual. No left gastric artery was found (Lewis et al., 2005)

The celiac trunk is the widest ventral branch of the abdominal aorta. The unusual embryological development of the ventral splanchnic arteries can lead to considerable variations (Cavdar et al.). The reported incidence of celiacomesenteric trunk varies between 1-2.7\% (Cavdar et al.). A recent study had reported the celiacomesenteric trunk with a right accessory hepatic artery; and a left colic artery arising from a portion corresponding to the superior mesenteric artery (Katagiri et al., 2007). As regarding the inferior phrenic artery, its origin from the from left hepatic or left gastric artery has also been reported (Tanaka et al., 2008). The anomalies pertaining to the inferior phrenic artery may be important for interventional radiologists.

Although, there is a past report of the celiacomesenteric trunk with renal vascular anomalies (Nayak, 2006), the combination of abnormal inferior phrenic artery with aberrant branch from the celiac trunk supplying the pancreas, duodenum is rare anomaly. We as anatomists believe that the concomitant variations of these type are be kept in mind by the surgeon while operating on carcinoma head of pancreas, during manipulation of the diaphragm and in cases of kidney transplantations.

The authors would like to reiterate the importance of pre-surgery investigations especially, angiography of the vascular tree of the abdomen for betterment of the patients.

JACOB, T.; MODGIL, V.; RANA, K. K. \& DAS, S. Múltiples anomalías vasculares en el abdomen - Un estudio anatómico macroscópico. Int. J. Morphol., 26(3):563-566, 2008.

RESUMEN: El conocimiento del patrón de ramificación de la aorta abdominal es clínicamente importante para cualquier cirujano abdominal que opere en partes del intestino o estructuras vecinas, como glándulas suprarenales, bazo, páncreas, hígado, riñones y uréteres. La presencia anormal de la arteria frénica inferior asociada con una rama aberrante originada del tronco celiaco, supliendo el páncreas y duodeno, es una variación anatómica rara. En el presente caso, se observaron cuatro ramas de la arteria celiaca: (a) arteria gástrica izquierda (b) arteria hepática común (c) arteria esplénica y (d) una rama aberrante, que tuvo un curso inferior hacia el páncreas. La arteria aberrante suministraba irrigación al cuerpo del páncreas y daba una rama para la parte horizontal del duodeno para luego entrar en el mesocolon transverso para irrigar la flexura hepática y algunas partes del colon ascendente y transverso. La arteria frénica inferior estaba ausente en el lado izquierdo. Anomalías concomitantes de este tipo deben ser consideradas por el cirujano, en casos de operación de carcinoma de cabeza de páncreas y la realización de trasplante renal.

PALABRAS CLAVE: Anomalía; Tronco celiaco; Rama; Frénico inferior; Arteria; Páncreas; Duodeno.

\section{REFERENCES}

Azagra, J. S.; Goergen, M.; Simone, P. D. \& Ibanez-Aguirre, J. Minimally invasive surgery for gastric cancer. Surg. Endosc., 13:351-7,1999.
Cavdar, S.; Gürbüz, J.; Zeybek, A.; Sehirli, U.; Abik, L. \& Ozdogmus $_{s}$, O. A variation of coeliac trunk. Kaibogaku Zasshi, 73:505-8, 1998. 
Dubois, F.; Berthelot, G. \& Levard, H. Cholecystectomy par coelioscopy. Nouv Presse Med., 18:980-2, 1989.

Karakose, M.; Peker, T.; Gulekon, N.; Yucel, D. \& Oktem, $\mathrm{H}$. Numerical variation of the celiac trunk and anatomical variation in origin and course of the dorsal pancreatic artery. Saudi. Med. J., 27:1232-5, 2006.

Katagiri, H.; Ichimura, K. \& Sakai, T. A case of celiacomesenteric trunk with some other arterial anomalies in a Japanese woman. Anat. Sci. Int., 82:53$8,2007$.

Kitano, S.; Iso, Y.; Moriyama, M. \& Sugimachi, K. Laparoscope-assisted Billroth I gastrectomy. Surg. Laparosc. Endosc., 4:146-8, 1994.

Lewis, S. J. Vascular anomalies of first and second unpaired branches of the abdominal aorta: A case study. Clin. Anatomy, 4:219-22, 2005.

Nayak, S. Common celiaco-mesenterico-phrenic trunk and renal vascular variations. Saudi Med. J., 27:1894-6, 2006.

Oran, A.; Yesildag. A \& Memis, A. Aortic origin of right hepatic artery and superior mesenteric origin of splenic artery two rare variations demonstrated angiographically. Surg. Rad. Anat., 23:349-52, 2001.

Standring, S. Gray's anatomy- The anatomical basis of clinical practice. New York, Elsevier/Churchill Livingstone, 2005.

Tanaka, R.; Ikebukuro, K. \& Akita, K. The left inferior phrenic artery arising from left hepatic artery or left gastric artery: radiological and anatomical correlation in clinical cases and cadaver dissection. Abdom. Imaging., 33(3):328-33, 2008.

Yamaki, K.; Tanaka, N.; Matsushima, T.; Miyazaki, K. \& Yoshizuka, M. A rare case of absence of the celiac trunk: the left gastric, the splenic, the common hepatic and the superior mesenteric arteries arising independently from the abdominal aorta. Ann. Anat., 177:97-100, 1995.
Corresponce to:

Prof. Kum Kum Rana, MBBS,MS

Department of Anatomy, Maulana Azad Medical College, Bahadur Shah Zafar Marg

New Delhi-110002

INDIA

Tel. 00-91-11-23239271 ext. 130 (Office),

00-91-11- $27843023(\mathrm{R}), 9818696101(\mathrm{M})$.

Email: kumkumrana@hotmail.com drkumkum.rana@gmail.com

Received: 09-01-2008

Accepted: 01-04-2008 